\title{
Correction to: Comprehensive analysis of prognostic gene signatures based on immune infiltration of ovarian cancer
}

Shibai Yan ${ }^{1}$, Juntao Fang ${ }^{2}$, Yongcai Chen ${ }^{3}$, Yong Xie ${ }^{3}$, Siyou Zhang ${ }^{3}$, Xiaohui Zhu ${ }^{4^{*}}$ and Feng Fang ${ }^{3^{*}}$

\section{Correction to: BMC Cancer 20, 1205 (2020) \\ https://doi.org/10.1186/s12885-020-07695-3}

Following publication of the original article [1], the authors reported a typesetting error in the arrangement of Figs. 2, 3, 4, 5, 6, 7, 8 and 9, as well as their corresponding captions. The correct figures and captions are given in this correction article and the original article [1] has been corrected.

\section{Author details}

'Department of Medical Oncology, the First Affiliated Hospital of Guangxi Medical University, Nanning 530021, Guangxi Zhuang Autonomous Region, China. ${ }^{2}$ Laboratory of Experimental Cardiology, Department of Cardiology, University Medical Center Utrecht, Utrecht 3584, CX, The Netherlands. ${ }^{3}$ Department of Obstetrics and Gynecology, The First People's Hospital of Foshan, 81 Lingnan North Avenue, Foshan 528000, Guangdong, China. ${ }^{4}$ Department of Pharmacology, College of Pharmacy, Shenzhen Technology University, Shenzhen 518118, Guangdong, China.

Published online: 12 January 2021

\section{Reference}

1. Yan S, Fang J, Chen Y, et al. Comprehensive analysis of prognostic gene signatures based on immune infiltration of ovarian cancer. BMC Cancer. 2020;20:1205. https://doi.org/10.1186/s12885-020-07695-3.

*Correspondence: zxh2681731@163.com; fangfeng_go@163.com

${ }^{4}$ Department of Pharmacology, College of Pharmacy, Shenzhen Technology University, Shenzhen 518118, Guangdong, China

${ }^{3}$ Department of Obstetrics and Gynecology, The First People's Hospital of Foshan, 81 Lingnan North Avenue, Foshan 528000, Guangdong, China

Full list of author information is available at the end of the article

(c) The Author(s). 2020 Open Access This article is licensed under a Creative Commons Attribution 4.0 International License, which permits use, sharing, adaptation, distribution and reproduction in any medium or format, as long as you give appropriate credit to the original author(s) and the source, provide a link to the Creative Commons licence, and indicate if changes were made. The images or other third party material in this article are included in the article's Creative Commons licence, unless indicated otherwise in a credit line to the material. If material is not included in the article's Creative Commons licence and your intended use is not permitted by statutory regulation or exceeds the permitted use, you will need to obtain permission directly from the copyright holder. To view a copy of this licence, visit http://creativecommons.org/licenses/by/4.0/ The Creative Commons Public Domain Dedication waiver (http://creativecommons.org/publicdomain/zero/1.0/) applies to the data made available in this article, unless otherwise stated in a credit line to the data. 


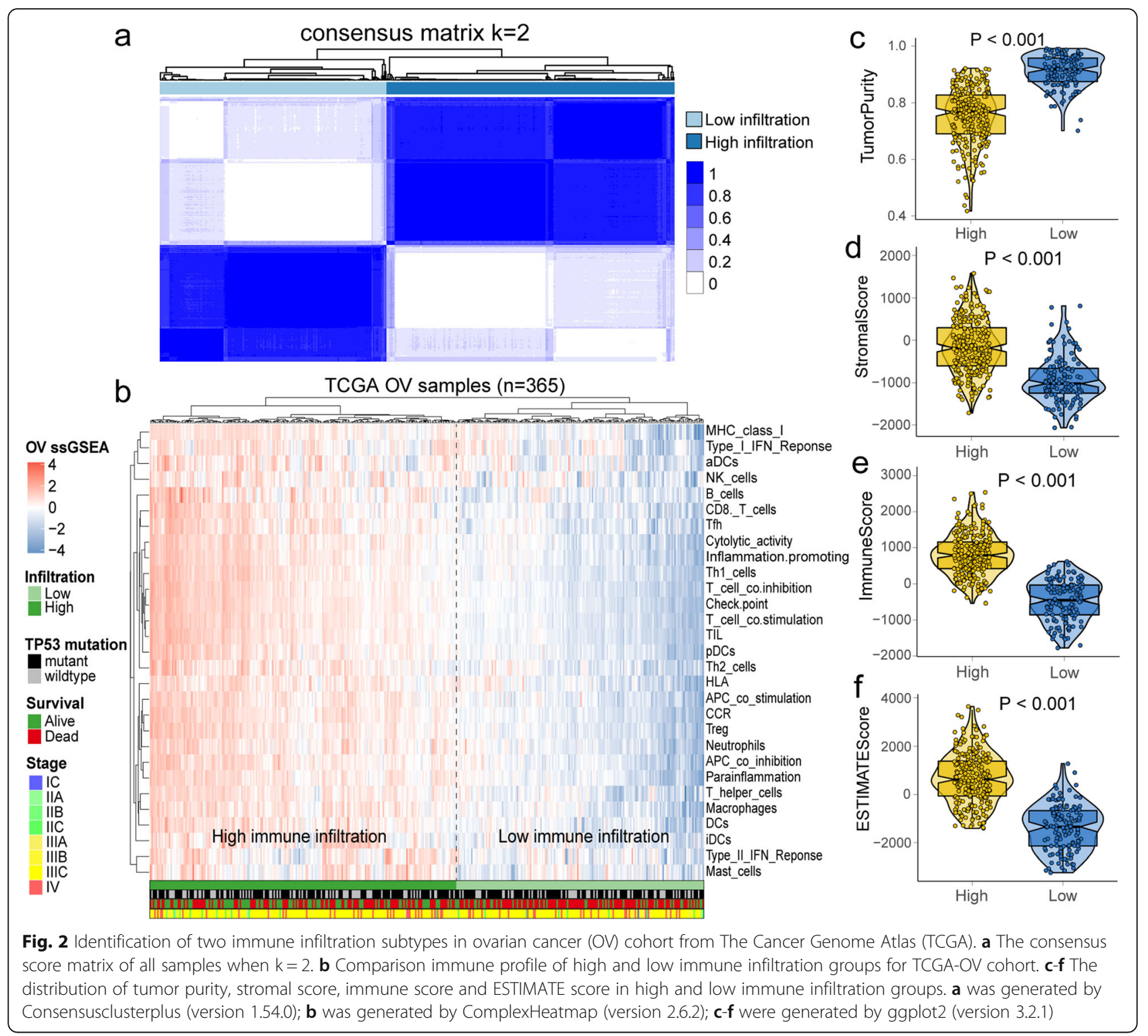



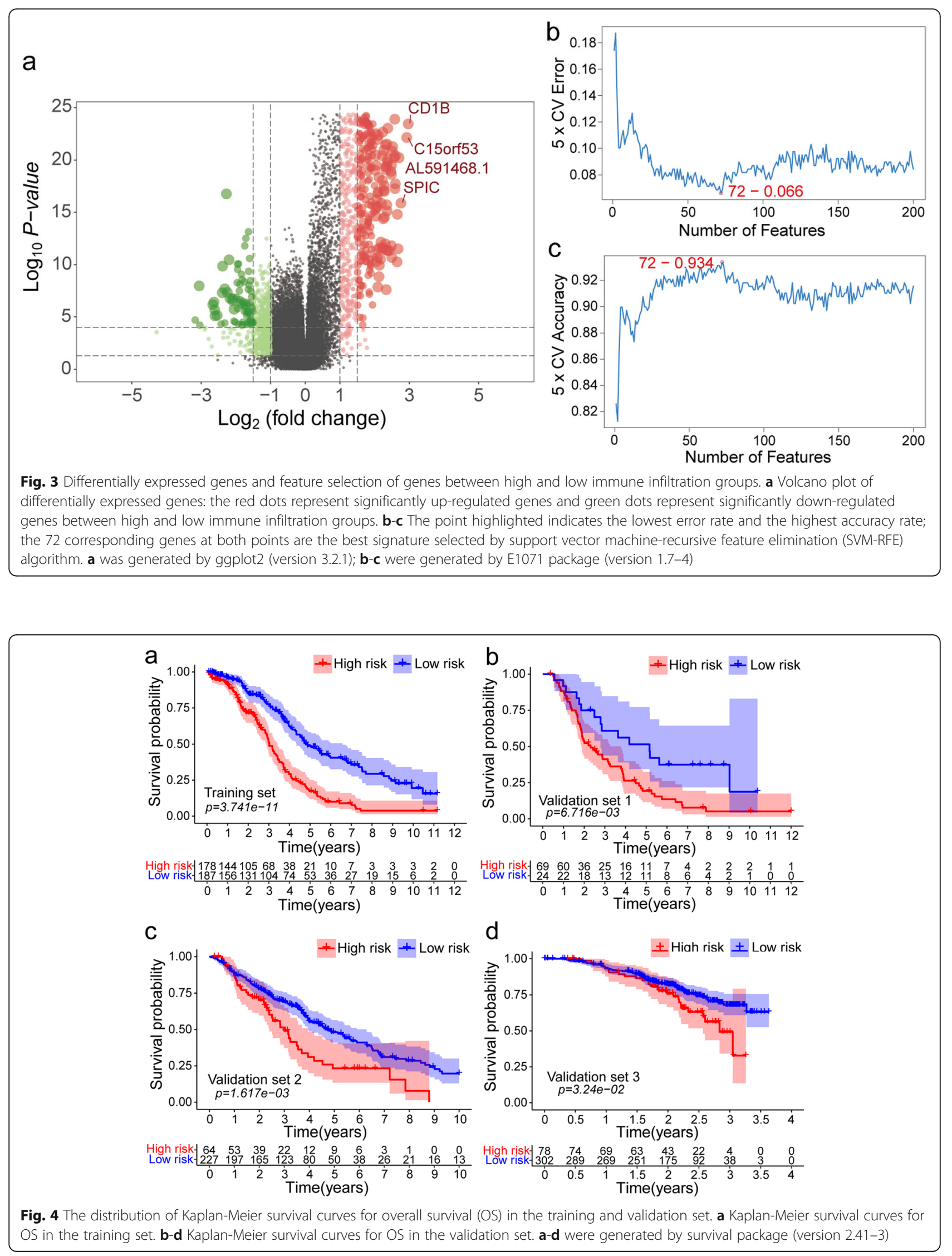

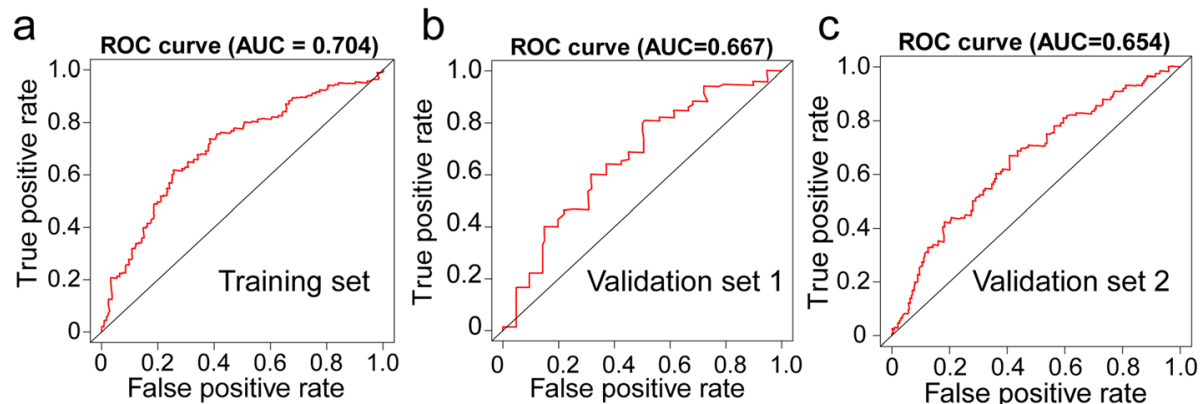

Fig. 5 The distribution of time-dependent receiver operator characteristic (ROC) curves for overall survival in the training and validation set. a ROC curve of training set with area under the curve (AUC) at 5 year. $\mathbf{b}-\mathbf{c}$ ROC curve of validation set with AUC at 5 year. $\mathbf{a}$-c were generated by survivalROC (version 1.0.3)

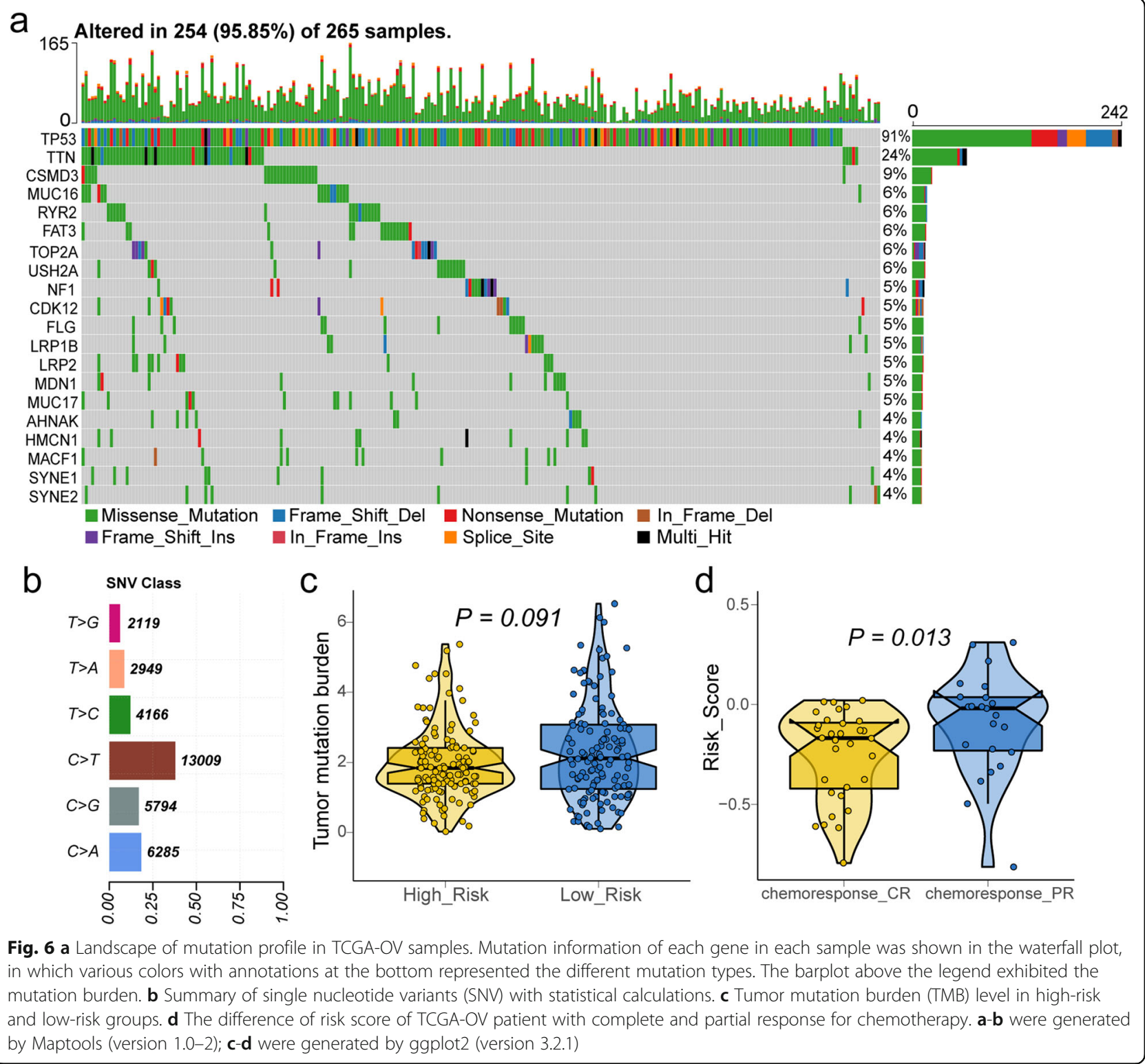




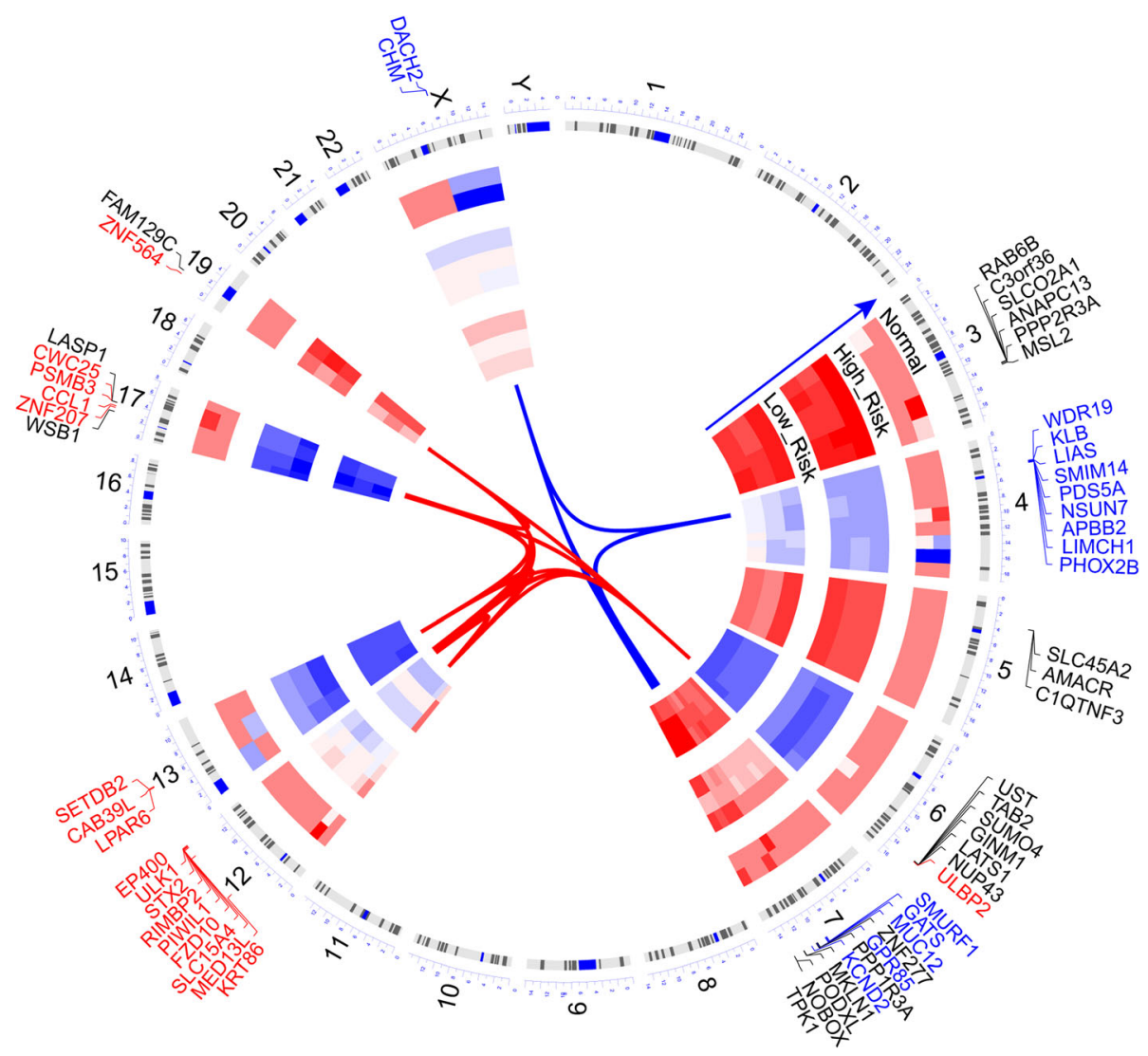

Fig. 7 Circus plots shows the difference of copy number variations (CNV) level of genome among risk and control groups of TCGA-OV. The graph reflects location of variant genes on chromosome, red genes represent exerting amplification of copy number $(>0.1)$ while blue genes mean deletion $(<-0.1)$, and black genes reflect $-0.1 \sim 0.1$ CNV level between high- and low-risk group. Figure was generated by OmicCircos (version 1.28.0) 


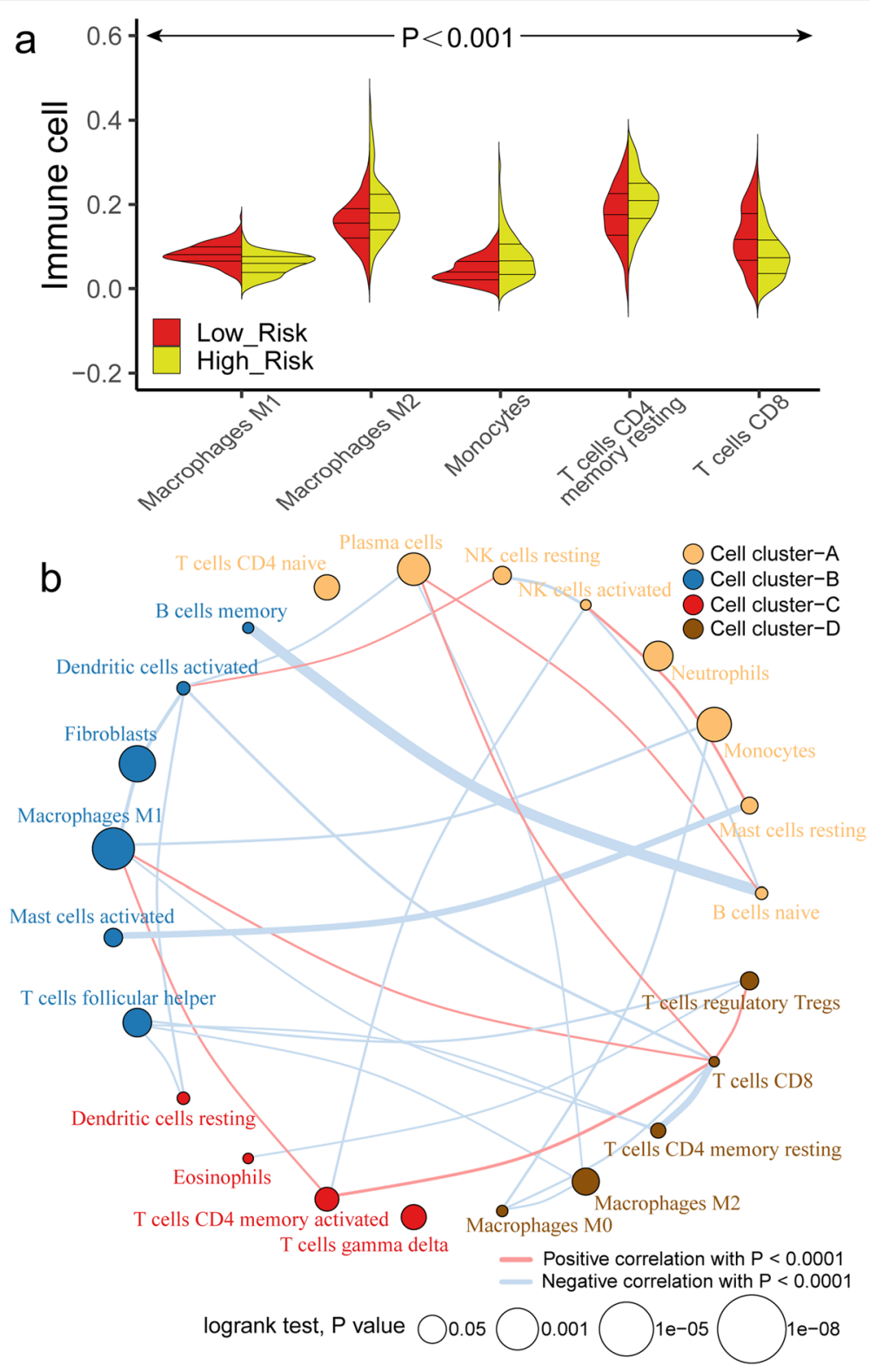

Fig. 8 The landscape of immune infiltration in the TCGA cohort. a The Violin plot shows the significant difference $(P<0.001)$ of immune cell fractions between high-risk and low-risk subgroup. $\mathbf{b}$ The interaction between 22 immune cells in TCGA-OV samples. The size of circle indicated the effect of each immune cell on the prognosis, and $P$ value was operated by Log-rank test. a was generated by ggplot2 (version 3.2.1); $\mathbf{b}$ was generated by Igraph (version 1.2.4.2) 


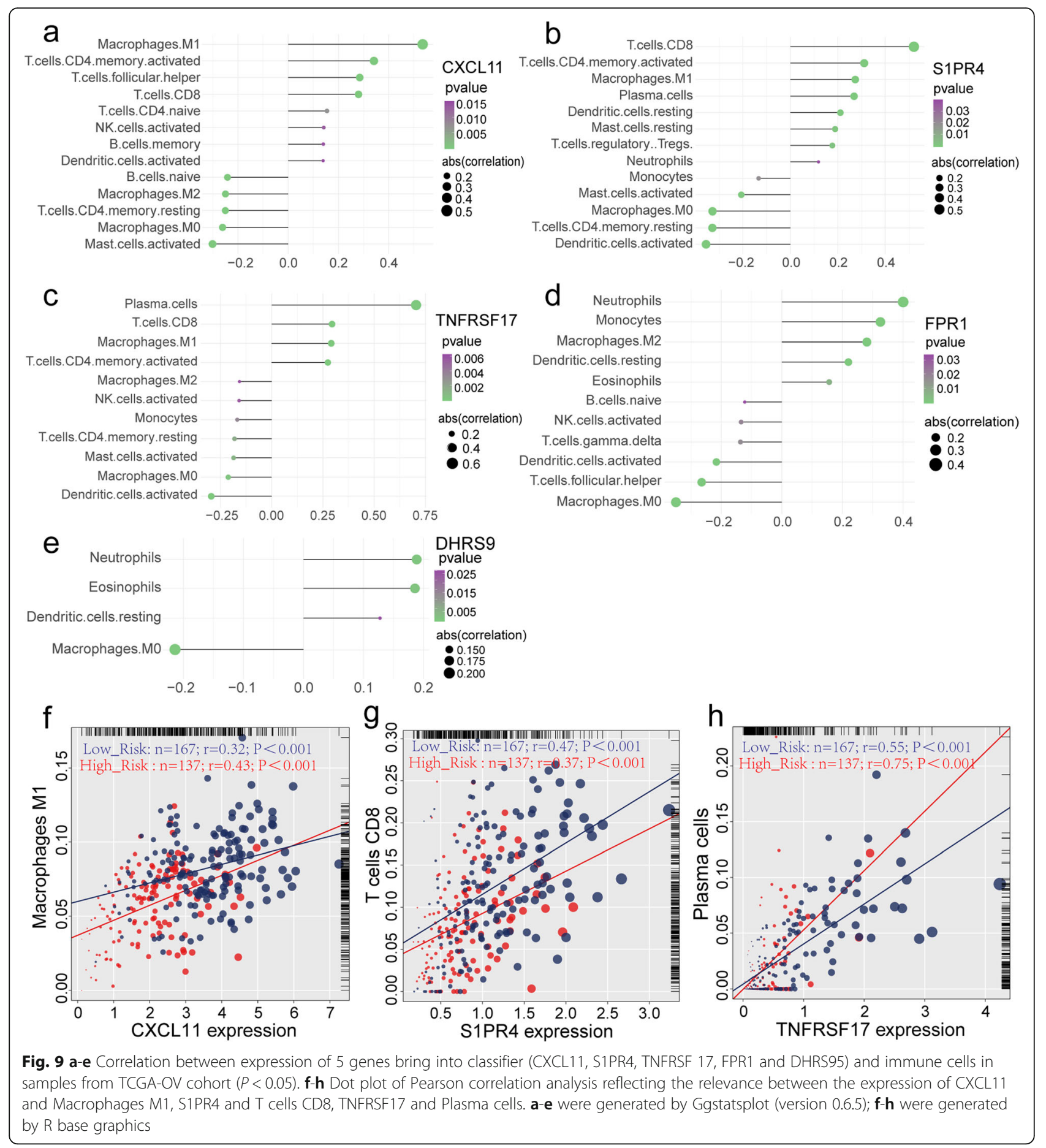

